\title{
Pesquisa
}

\section{DANÇA COMO ARTE MILENAR NUMA ABORDAGEM CONTEMPORANEA}

\author{
Cicera Patricia Moreira (1) \\ José Cleostenes de Oliveira (2)
}

\begin{abstract}
Resumo
A dança é uma das maneiras mais divertidas e adequadas para ensinar, na prática todo potencial de expressão do corpo humano, pois além de trabalhar o desenvolvimento motor, ajuda a desenvolver a linguagem diferente da fala e escrita, conseguindo melhorar a sociabilidade e quebrar a timidez e sendo uma característica e tradição de todos os paises e região, tornando-se uma diversidade cultural. E este artigo tem como objetivo mostrar a dança como prática pedagógica na escola sendo instrumento de elevar a auto-estima, melhorar as relações pessoais e grupais dos alunos, buscando desenvolvimento, atitudes facilitando a comunicação de si mesmo com o mundo. O presente trabalho justifica-se pela importância de apresentar a dança como elemento primordial para o desenvolvimento do educando. Para tal foi utilizada uma bibliografia ampla para atingir o objetivo almejado, e diante do estudo podese concluir que a prática da dança na escola é um veículo que contribui para a formação de alunos desde profissionalmente e psicologicamente.
\end{abstract}

Palavras-Chave: Dança. Prática Pedagógica. Cultura. 


\section{Introdução}

A Educação Física tem em seus fundamentos as concepções no corpo e movimento, e contempla múltiplos conhecimentos produzidos e usufruídos pela sociedade a respeito do corpo e do movimento; nas quais estão ligadas as atividades culturais, afeto e emoção com objetivos de expressão de sentimentos, lazer e saúde.

A Educação Física escolar pode proporcionar situações de aprendizagem, criando ao educando oportunidades de desenvolver suas potencialidades de forma humanitária. Para que esse fato ocorra são oferecidas diversas atividades como a dança que se torna fundamental para que o aluno eleve sua auto-estima e melhore seus relacionamentos com o mundo se tornando sociável e valorizador da diversidade cultural.

Dançar é aprofundar o sentimento e o conhecimento da vida do corpo retratada por expressões sensoriais, imagéticas, emotivas, empregadas do saber dos sabores. Sensações que nascem do contato com efeitos ou emanações do sujeito e objeto as que dizem respeito.

“A dança expressa por meio de movimentos corpóreos e rítmos nossa consciência de participar no mundo da natureza". A dança faz o corpo físico um instrumento para a manifestação de culturas como expressões de estados emocionais e de conceitos espirituais de tal intensidade que devem manifestar-se através de instrumentalidade do corpo físico. Ela expressa a vida interna do que em seu corpo físico, a sua consciência, o seu coração, seus sonhos, temores, amores, desvios, aspirações e entendimentos. Viver não é simplesmente mover-se através do tempo de colocação do espaço. Viver é mover-se através da evolução de um ponto ao outro da consciência. Dançar significa identificar seu ser com movimentos cósmico, que é a ação alquímica da vida, por meio de seqüências rítmicas de posições corpóreas.

Assim a dança ocupa um papel essencial na vida do se humano, pois está voltada para transmitir sentimentos, expressar movimentos do corpo e se tornando a consciência do ser.

Contudo até a natureza usa a dança como forma de interagir com o mundo, as pessoas formando todo um único conjunto.

$\mathrm{Na}$ dança, atualmente, a criatividade vem sendo abordada apenas no processo de composição do produto artístico, normalmente pelo professor-coreógrafo. A visualização desta arte como movimentos expressivos, considerados além da mera imitação reprodutiva; além do aprender/executar passos; implica que a expressão criadora intencional, implícita na composição de um produto coreográfico, também se faça presente nos distintos momentos inerentes a essa prática artística e seu ensino. 
E o que trata esse trabalho de estudo é a prática da dança na escola, onde será abordado aspectos conceituais da mesma segundo diversos autores, tipos de dança e a dança como prática pedagógica de acordo com os Paramêtros Curriculares Nacionais e outros autores que estudam sobre o tema.

\section{Aspectos Conceituais}

A dança é uma das mais belas formas de comunicação humana capaz de transmitir sentimentos que não podemos expressar com palavras, além de ser um meio para promover a harmonia entre as pessoas e, sem dúvida, um instrumento muito importante para o desenvolvimento social, emocional e cultural de crianças e adolescentes em processos formais de educação.

Segundo Coletivo de autores (1992, p.82) "A dança é considerada uma expressão representativa de diversos aspectos da vida do homem". Ou seja, considerada como linguagem social que transmite sensações e sentimentos vividos seja: alegria, hábitos, religião e etc.

"A dança surge da necessidade humana de se identificar com a eterna roda das forças criativas do cosmos" (PORTIEREARI, 1995, p. 45). Sendo assim, a dança foi concebida como um meio importante para que o homem pudesse organizar a sua vida dando mais sentido e maior harmonia com as forças naturais e, portanto, desenvolver um maior diálogo entre os seres humanos. Através dessa nova cultura pode-se inferir que ele se tornou mais instrumentalizado para entender a si mesmo e o mundo ao seu redor.

Ainda, a referida manifestação cultural orientou o homem para que esse utilizasse os meios mais apropriados no ato da comunicação, seja para se expressar ou ser compreendido e entender as ações das outras pessoas, movida por forças transcendental sendo também a mais antiga das artes. Assim, esse é um meio de expressão utilizada pelos homens, sejam cultos ou não para dizer o que não conseguem através das palavras.

"A dança é uma manifestação de movimentos e liberdade em sintonia com o ritmo e o corpo." (GARANUDY, p.35). Assim, a dança se torna parte de equilíbrio entre o corpo e o mundo que o cerca.

Huizinga (1996, p.189) coloca que: 
A dança é especialmente identificada como jogo por conta de característica de ser fundamentalmente ação de serem apreciados enquanto a ação que se repete. Executados diante de um público, caracterizam-se naquele instante, agindo sobre o espaço e o tempo, em permanente alteração, se tornando uma linguagem artística que é simutalmente musical, porque tem movimento e ritmo.

Assim como a dança, outras expressões artísticas, incluindo desempenho, conquistam um caráter lúdico quando estimulam a participação, o uso informal do espaço e a inclusão diferenciada do público na obra de arte.

\section{A Dança nos primórdios}

\section{No paleolítico}

Segundo Faro: “os primeiros registros de danças datam do paleolítico superior e não tinham a intenção de cultuar deuses ou indicação de vida após a morte”. (p. 38)

Ainda Faro "Existe, em muitas cavernas, a representação de figuras humanas disfarçadas de animais, numa atitude dançante destinadas a alcançar aquele intento” (p. 40). Estes relatos constam que o homem neste período já praticava o culto à dança.

Eliana Caminada (2008, p.42) relata:

A dança no Período paleolítico inferior - primitiva cultura básica: dança circular sem contato. Período paleolítico médio culturas básicas médias: pigmeus (dança circular sem contato e danças animais) e pigmóides (dança circular sem contato e danças convulsivas). Período paleolítico superior último culturas básicas: tasmanóides e australóides (dança circular sem contato, danças animais, danças serpentinas e danças sexo-lunare).

Assim O homem técnico do paleolítico inferior, já conhecia as figuras do círculo sem contato quando aprendeu a dominar algum jogo e a inventar um tipo de arma para se defender. 
Ainda Eliana Caminada (2008, p.60) afirma que:

Já no seu primórdio a dança foi uma manifestação naturalista. À repetição sincronizada de gestos, inicialmente desordenados, pode-se considerar como a primeira técnica desenvolvida pelo ser humano. Repetida, usando mais elementos e uma gradativa estilização, a seqüência de movimentos foi se constituindo numa coreografia.

Contudo, a autora enfatiza, o surgimento da primeira técnica de desenvolvimento coreográfico criado pelo homem, conquistando assim um grande marco na dança.

\section{Neolítico}

Para Faro: "O homem nesse período é movido por uma crença em espíritos a quem adorava e cultuava, e em acreditava numa força superior e sobrenatural". (p. 40)

Assim diante dessa adoração o homem passou a utilizar a dança nas cerimônias e cultos executada por magos, Xamãs e sacerdotes.

\section{A Dança na antiguidade}

“Nesse período a dança passou a ser considerada uma obra sagrada para que o homem pudesse se aproximar dos deuses e se consagravam como semideus". (FARO, p. 44).

Isso significa que a dança era considerada como um ritual de comunicação e consagração entre o homem e os deuses.

De acordo com: Ossana Paulina (1988, p.35)

A dança está relacionada à celebração dos mistérios dos deuses gregos, como função, tratar as mulheres histéricas fazendo-as danças até exaustão e os mistérios de Zeus pai dos deuses cujas danças mágicas eram dançadas pelas curetas mestres em danças que recebiam as comunicações dos oráculos e mensagens das forças sobrenaturais. 
Isso quer dizer que a dança era praticada como caráter de comunicação com os deuses, e se tornando como força de combater problemas nas suas vidas.

Segundo a Revista Nova Escola (2006, p.28),

Na Grécia, a arte de dançar foi facilmente acessível a todos os cidadãos e constituía parte importante no ritual religioso, do drama, da educação e do divertimento. E, porém em Roma era considerada incompatível com o espírito do povo, era pecado.

Ou seja, a presença da dança na Grécia era essencial, pois transmitia diversão e cultura ao povo, porém em Roma a prática não podia harmonizar o ambiente, pois era considerada preconceituosa diante da igreja.

\title{
A dança na idade média
}

Faro (1986, p.50) descreve que:

\begin{abstract}
A dança na idade média como uma atividade recreativa, não profissionalizada e a distingue de acordo com as três classes sociais da época, a saber: Campestre (danças populares realizadas nas aldeias caracterizadas como alegres, saltitante e representam aspectos da vida pastoral), Nobreza (eram caráter lentas e disciplinadas e desenvolvidas pelos nobres nos castelos) e Mouriscas (representava a luta dos cristãos contra os mouros junto a lendária figura de EI Cid. Eram populares, dançadas em público e foi difundida em toda a Europa).
\end{abstract}

O autor faz uma descrição da dança no período da idade média, e como as mesmas são praticadas por classes sócias diferentes, como na campestre que está voltada para culturas de vida populares já na nobreza apresentava-se de caracter de disciplina e ritmo simples, e finalizando com as mouriscas que eram desenvolvidas também como populares, porém com uma diferença a mesma foi expandida por toda a Europa. 


\section{A dança no renascimento}

“O renascimento gerou uma visão inédita de mundo, uma nova forma de interpretar a antiguidade clássica, elaboração de novos conhecimentos sobre o homem e o cosmos. Além disso, a pratica do assalarimento passou a ser praticada o que não existia no modelo feudal". (FARO, p.42).

Segundo o autor supracitado, a dança na renascença era uma atividade lúdica realizada nas aldeias, mais precisamente, nas praças, salões e castelos, e também trazendo transformações na forma de interpretação e conhecimento sobre a dança.

\section{Tipos de Danças}

Portiereari, Maribel. (1989, p.62)

À medida que as civilizações iam florescendo, as formas de danças iam se estruturando e se formando típicas dos grupos étnicos e sociais que as praticavam, além de manter o seu relacionamento com a arte de representação (teatro) em suas formas mais primitivas e sendo classificadas de acordo com a cultura de cada povo.

Assim de acordo com o surgimento de novas civilizações a dança foi se firmando e construindo novos ritmos.

Danças Sagradas: danças de conexão direta, religiosas, ritos de iniciação, expiação contento traços muitas vezes de natureza erótica ou lasciva, ou de caráter guerreiro, veneratório, propiciatório de chuvas, de fertilização e de agradecimento.

Dança Profana: relacionadas diretamente ao divertimento público, possui características populares que enfatizam as relações do homem no cotidiano com o seu meio social.

Funerárias: danças sacras dedicadas ao cortejo fúnebre cujas coreografias tinham como intuito, facilitar a entrada do defunto no além.

Mesopotâmia: as danças dos Assírios e Caldeus foram descritas em baixos relevos, em murais e esculturas descobertas em escavações arqueológicas. Eram danças de caráter veneratório em homenagem aos deuses Baal, Moloch, Nabo, e Astart. 


\section{A dança na Atualidade}

Segundo: Isadora Duncan "a dança é uma verdadeira liberação (e as antigas limitações puritanas e a conquista de um equilíbrio real, ou se apenas uma das formas pela qual nossa sociedade perpetua sua força repressiva)”. (p. 38)

Desse o modo a autora afirma que a dança é uma fonte de equilíbrio, liberdade e aumenta a força expressão.

De acordo com Revista Nova Escola: “A renovação da dança é inseparável da profunda mudança por que passam as linguagens estéticas no século XX”. (p. 50)

Portanto a expressões artísticas existem sempre e acompanham as transformações da dança.

\section{Forró}

O Forró é uma dança composta de gêneros musicais que predomina principalmente na regiãomas se espalha com sucesso por todo território nacional. O forró é dançado em duplas, casais, que executam diversas evoluções, diferentes para o forró nordestino e o forró universitário. A diferença principal entre esses dois forrós é que o Nordestino tem mais malícia, sensualidade, e exige mais cumplicidade dos parceiros. O Forró universitário tem mais evoluções. Assim o Forró representa sensualidade e criatividade diante de inonações realizada por cada casal praticante.

\section{Samba}

O Samba é a principal forma de música de raízes africanas surgida no Brasil, um ritmo religioso, cujo nome significa umbigada, devido à forma como era dançado.

\section{Funk}

O Funk é um estilo bem característico da música negra norte-americana, desenvolvido por artistas como $\underline{\text { James Brown e por seus músicos, especialmente Maceo Parker e Melvin }}$ $\underline{\text { Parker. }}$ 


\title{
Rock
}

Rock and roll (também escrito rock 'n' roll) é um gênero de música que emergiu e se definiu no sul dos Estados Unidos durante a década de 50, rapidamente se espalhando pelo resto do mundo. Evoluiu mais tarde para diversos sub-géneros no que hoje é definido simplesmente como "rock". Atualmente, o termo "rock and roll" tem diversos significados, seja para definir o rock tradicional ao estilo dos anos 50, ou para definir o rock surgido posteriormente, e até mesmo certas vertentes da música pop.

\section{Sertanejo}

É conhecida comoCaipira ou sertaneja a execução composta e executada das zonas rurais, do campo, a antiga Moda de viola.

\section{A Dança como Prática Pedagógica}

\author{
Segundo Vygotsky (1978,p. 40)
}

Ao entendermos que, na dança, o sujeito se estrutura e interage com o outro numa relação intercomplementar de troca e, visualizando-a como uma linguagem artística composta por um conjunto de signos estéticos nos qual o sujeito, por meio de seu sentimento-idéia, constrói formas que devem refletir conteúdos, somos direcionados a procurar maneiras de ensinar que explorem a criatividade dos sujeitos envolvidos no processo.

De acordo com o autor a dança se torna instrumento de aproximação entre os alunos, composto de troca de experiências e idéias as quais lhe ensinam a explorar sua criatividade e construindo um hambiente harmonioso.

Ainda Vygotsky, "A criatividade do aluno deve ser enfatizada e estimulada durante as aulas. Os professores devem criar coreografias que serão interpretadas e transformadas em movimentos por seus alunos-intérpretes-criadores". Ou seja, os temas devem ser trabalhados, tanto em aula quanto em produtos coreográficos trazidos pelos professores. 
Desta forma, os alunos terão oportunidades de expressarem suas idéias, tornando-se de fundamental importância refletir sobre modos de desenvolvermos a criatividade nas aulas de preparação técnica, nos processos de criação/composição coreográfica, nas apresentações ou desempenho, bem como nas apreciações estéticas.

De acordo com Verderi (1998, p.60),

Considera-se a Dança uma expressão representativa de diversos aspectos da vida do homem; uma aula de Dança na escola permite ao professor conhecer melhor o seu aluno, ou seja, saber suas preferências sobre o que gosta de brincar, de cantar, de ouvir; discutir suas experiências; fazer fluir sua imaginação e verificar a influência dela na realidade e nas atitudes da criança.

Isto quer dizer que a prática da Dança na Educação Física tem que estar voltada não só para a recreação, ou simplesmente para o treino de habilidades motoras, mas para o equilíbrio psíquico, para a expressão criativa e espontânea, a fim de assegurar aos alunos a possibilidade de reconhecimento e compreensão do universo simbólico e bem como para que isso aconteça o professor deve pedir sugestões de estilo e ritmo de preferência do aluno, havendo um intercâmbio entre ambos.

Pereira (2001, p.25) coloca que:

A dança é um conteúdo fundamental a ser trabalhado na escola: com ela, podem-se levar os alunos a conhecerem a si próprios e/com os outros; a explorarem o mundo da emoção e da imaginação; a criarem; a explorarem novos sentidos, movimentos livres.

Assim a dança pode ser uma ferramenta preciosa para o indivíduo lidar com suas necessidades, desejos, expectativas e também servir como instrumento para seu desenvolvimento individual e social.

Segundo PCN's “para o ensino da dança deve se considerar que o aspecto expressivo se confronta, necessariamente, com a formalidade da técnica para sua execução, o que pode vir esvaziar o aspecto verdadeiramente expressivo". Assim deve-se ensinar a dança como: arte e não como: transposição de vida, pois se isso não ocorrer ela a sua representação se torna sem sentido. 
De acordo com os PCN's (p.51) “As danças determinam meios de expressão de cada aluno, o que requer habilidades corporais".

Contudo, o aluno ao aprender a dançar, desenvolve diversas agilidades, flexibilidade, conhecimento sobre o corpo limitações e superações, favorece o surgimento da expressão espontânea eleva a sua auto-estima, melhorar suas relações pessoais, grupais entre colegas, professores e exprime seus pensamentos se tornando ativo no processo de aprendizagem.

Segundo Piaget e Vygostsky (1932, p.47) a aprendizagem ocorre através das relações externas e internas de um indivíduo e que este processo se dá através da genética de um indivíduo, do meio em que vive e das tarefas que realiza. Isso intensifica a importância de ser trabalhado na escola a dança no processo de ensino-aprendizagem, pois em uma aula o aluno recebe novas informações, relacionando com as já existentes e com o meio em que está, criando novas informações, gerando conhecimento.

Ainda PCN's (p.53) "Nas atividades rítmicas e expressivas é possível combinar a marcação do ritmo com movimentos coordenados entre si, essas manifestações culturais em combinação com o ritmo, velocidade, intensidade $e$ fluidez, podem ser aprendidas $e$ recriadas”.

Assim o aluno desenvolver sua criatividade na criação de novas coreografias e aprendizagem não se torna repetitiva e monótona, levando o aluno a um aprendizado divertido, enriquecedor, voltado para mudanças.

Segundo os PCN's: A diversidade cultural que caracteriza cada País tem na dança uma das expressões mais significativas, constituindo um amplo leque de possibilidades de aprendizagem.

Todavia, o conhecimento sobre a variedade de danças que contém cada País é necessário para que o aluno aprenda a conhecer, vivenciar, valorizar, respeitar e apreciar as manifestações culturais, se tornando crítico, participativo e atuante.

Gallahue afirma que: “O professor fundamentado nos princípios da dança criativa proporciona ao educando atividades que podem estimular motivar, desenvolver e comunicar idéias e movimentos; fazendo uma interação entre as crianças e o ambiente”. (p.40) Ou seja, estas atividades estimulam a capacidade de solucionar problemas de maneira criativa; desenvolvem a memória; o raciocínio; a socialização; auto confiança e auto estima; fazendo com que o indivíduo tenha uma melhor relação com ele próprio e com os outros

Ainda PCN's “por meio das danças os alunos poderão conhecer as qualidades do movimento expressivo como leve/ pesado, forte/fraco, rápido/lento, fluido/interrompido, direção, intensidade, duração”. (pág. 53) 
Sendo assim o aluno capaz de analisá-los a partir de esses referenciais conhecerem técnicas de execução de movimentos e adotar atitudes de valorização e apreciação dessas manifestações expressivas.

Para despertar nos alunos o interesse pela dança, é preciso levar em consideração o repertório artístico que eles têm deixar bem claro que homem também dança e, claro, convidar a turma a participar. Assim o professor deve procurar métodos para faz com todos os alunos participem, na qual ele deve usar um repertório adequado para cada um visando atender suas necessidade e atingindo o seu objetivo que é o envolvimento do aluno.

Para Jean Piaget (1932, p.55)

Dentro da área de educação, a dança criativa ou educativa propícia aos alunos, o auto-conhecimento; as vivências de corporeidade; relacionamentos estéticos com outras pessoas e com o mundo; incentiva a expressividade artística e humana; libera a imaginação, a criatividade; sendo uma forma de comunicação e de conhecimento, ajudando na formação dos cidadãos.

Sendo assim, a dança integra corpo e mente, trazendo aos alunos relações entre o mundo à sua volta e com si mesmo.

De acordo com Coletivo de Autores (p. 43) "A Dança na escola, associada à Educação Física, deverá ter um papel fundamental enquanto atividade pedagógica e despertar no educando uma relação concreta sujeito-mundo".

Assim o professor como mediador do conhecimento Deverá propiciar atividades geradoras de ação e compreensão, favorecendo a estimulação para ação e decisão no desenrolar das mesmas, e também reflexão sobre os resultados de suas ações, para assim, poder modificá-las defronte a algumas dificuldades que possam aparecer e através dessas mesmas atividades, reforçarem a auto-estima, a auto-imagem, a autoconfiança e o autoconceito.

O professor não deve ensinar o aluno como se deve dançar, mas sim favorecer a aprendizagem. Não deve demonstrar os movimentos, mas sim criar condições para que o aluno se movimente. Aqui, a dança não tem regras, não tem fazer certo ou errado (FERREIRA, 2005 ).

Contudo o professor deverá despertar a criatividade do aluno e que todo movimento é válido, desde que elaborado a partir da concepção de movimento que o aluno possui. 


\section{Considerações Finais}

A prática da Educação Física na Escola poderá favorecer a autônima do aluno para monitorar suas próprias atividades, construindo metas conhecendo seus potenciais e limitações.

A dança permite materializar o movimento da vida e por isso adquire diferentes formas, ritmos e intensidades conforme a época, as influências culturais e as tendências pessoais. Num sentido mais amplo a dança pode existir em todas as possibilidades de movimentos: nos animais, na natureza, nas emoções, nos pensamentos e nas relações humanas transformando o mundo.

A dança como arte, seja qual for seu estilo, traz ao público além de lazer, uma nova forma de ver a vida, o mundo real e o mundo irreal; traz ao espectador o quê as palavras não são capazes de dizer e o quê é capaz de sentir; a dança em si tem o poder de criar um mundo diferente na mente de cada espectador, e este mundo é capaz de gerar novas informações e conhecimentos para uma vida.

Portanto, a Prática da dança na escola é um veículo que contribui para a formação do aluno desde profissionalmente á psicologicamente, pois a prática estreita os laços de afinidade entre alunos, professores e um ambiente tranqüilo, ético, moral a qual o respeito, a aprendizagem são pontos essenciais que levam o aluno a ser criativo, motivado, conhecedor de culturas e apto para atuar na sociedade.

\section{Referências}

BRASIL, MINISTÉRIO DA EDUCAÇÃO, PARÂMETROS CURRICULARES NACIONAIS, Imprensa Oficial, Brasília 1997.

COLETIVO DE AUTORES, Metodologia do Ensino de Educação Física. São Paulo: Cortez, 1992.

ELIANA CAMINADA, História da Dança - Evolução Cultural, Editora Sprint, Rio de Janeiro, 2008.

FARO, Antônio, José. Pequena História da Dança. Rio de Janeiro: Jorge Zahar Editor, 1986. 
FERREIRA, V. Dança escolar: um novo ritmo para a Educação Física. Rio de Janeiro: Sprint, 2005.

GARANUDYU, Roger. Dançar a Vida. Rio: Nova Fronteira, 1980.

GALlAHUE, D. L.; CLELAND, F. Developmental Physical Education for all children. 4 th. ed. Champaign: Human Kinetics, 2003.

VANJA FERREIRA Dança Escolar - um novo ritmo para a educação SPRINT EDITORA 1 2005

HUIZINGA, Johan. Homo Ludens. São Paulo, Perspectiva, 1996.

OSSONA, Paulina. A Educação Pela Dança. São Paulo: Summus, 1988.

PEREIRA, S. R. C. Dança na escola: desenvolvendo a emoção e o pensamento. Revista Kinesis, Porto Alegre, 2001.

PORTIEARI, Maribel. História da dança. São Paulo. Rio de janeiro: Nova Fronteira. 1989.

REVISTA, Nova Escola. Setembro. 2006.

VERDERI. E.B.L.P. Dança na Escola. Rio e Janeiro: SPRINT, 1998.

VIGOTSKY Vida e educação. Rio de Janeiro: Melhoramentos, 1978.

\section{Sobre os autores:}

(1) Cicera Patricia Moreira é Graduada em Educação Física pela Universidade Estadual Vale do Acaraú -UVA. Aluna do curso de Especialização em psicologia Aplicada à Educação pela Universidade Regional do Cariri - URCA.

E-mail: patyedfisica2006@hotmail.com

(2) José Cleostenes de Oliveira é Professor da Universidade Vale do Acaraú - UVA. 